\title{
Alveolar distribution in french rolls made using taro mucilage
}

\author{
Distribuição alveolar do pão tipo francês usando a mucilagem \\ do taro
}

\author{
Carolina Cristina Bicalho ${ }^{1 *}$ (D), Raul Antônio Viana Madeira², Joelma Pereira², \\ João Domingos Scalon ${ }^{1}$
}

${ }^{1}$ Universidade Federal de Lavras (UFLA), Departamento de Estatística, Lavras/MG - Brasil

Universidade Federal de Lavras (UFLA), Departamento de Ciências de Alimentos, Lavras/MG - Brasil

*Corresponding Author: Carolina Cristina Bicalho, Universidade Federal de Lavras (UFLA), Departamento de Estatística, Campus Universitário, Caixa Postal 3037, CEP: 37200-000, Lavras/MG - Brasil, e-mail: carolinabicalho@gmail.com

Cite as: Bicalho, C. C., Madeira, R. A. V., \& Pereira, J., Scalon, J. D. (2019). Alveolar distribution in french rolls made using taro mucilage. Brazilian Journal of Food Technology, 22, e2018006. https://doi.org/10.1590/1981-6723.00618

\begin{abstract}
Emulsifiers are responsible for forming a dough that contributes to the retention of gluten in alveoli, the gas produced by the yeast, thus increasing the volume and softness of the bread. There are indications that hydrocolloids, such as taro mucilage (Colocasia esculenta), can present similar characteristics to emulsifiers. The presence of arabinose and galactose in the taro mucilage is responsible for the formation of a complex with proteins, called Proteoglycan arabinogalactan, that could present substantial emulsifying power, consequently favouring gas retention in the alveoli. Thus, the quantity, distribution and size of the alveoli must be analysed for the effective quality control of the breadmaking process, and this is therefore recommended. Conventional statistical methods are already used regularly in analyses of these variables, although spatial statistics have not been used for this purpose. In this paper, the authors defend the application of univariate point processes that have not been applied to the analysis of the spatial distribution of the alveoli in French bread made with taro mucilage. The results showed that these methods made it possible to characterize the spatial distribution of alveoli in French bread, demonstrating that the use of taro mucilage provided a good alveolar distribution in French type bread.
\end{abstract}

Keyword: Kernel estimation; Function K; Bread making; Simulation; Frozen storage; Microstructural.

\section{Resumo}

Os emulsionantes são responsáveis pela formação de uma massa que contribui para a retenção de glúten em alvéolos, o gás produzido por levedura, aumentando assim o volume e a suavidade do pão. Há indícios de que os hidrocoloides, como a mucosa de taro (Colocasia esculenta), podem apresentar características semelhantes às dos emulsionantes. A presença de arabinose e galactose na mucosa de taro é responsável pela formação de um complexo com proteínas, chamado Proteoglycan arabinogalactan, que poderia apresentar um poder emulsionante substancial e, consequentemente, favorecer a retenção de gás nos alvéolos. Assim, a quantidade, a distribuição e o tamanho dos alvéolos devem ser analisados para um controle de qualidade efetivo no processo de fabricação de pão e, portanto, tal análise é recomendada. Métodos estatísticos convencionais já são usados regularmente nas análises dessas variáveis, embora as estatísticas espaciais não tenham sido utilizadas para esse fim. Neste artigo, defendemos a aplicação de métodos de processos pontuais univariados que não tenham sido aplicados na análise 
de distribuição espacial de alvéolos localizados em pão francês com mucilagem de taro. Os resultados mostraram que esses métodos possibilitaram caracterizar a distribuição espacial dos alvéolos no pão francês, demonstrando que o uso da mucilagem de taro fornece uma boa distribuição alveolar ao pão tipo francês.

Palavras-chave: Estimativa do kernel; Função K; Fabricação de pão; Simulação; Armazenamento congelado; Microestrutural.

\section{Introduction}

In breadmaking, various emulsifying agents are used in the dough in order to reduce the loss of moisture, increase softness and, consequently, extend the shelf-life. Thus, many additives are included in the bread formula in order to improve the potential of the sensory characteristics, such as hydrocolloids (Bárcenas \& Rosell, 2007), enzymes and emulsifiers (Goesaert et al., 2005; Gomes-Ruffi et al., 2012). Emulsifiers are capable of forming films at the bread mass interface between the gluten and starch, increasing the ability of the dough to retain the gas produced by yeasts and, as a consequence, increase the volume and softness of the bread (Gomes-Ruffi et al., 2012; Krog, 1981).

Some hydrocolloids have effects that are similar to those of emulsifiers (Bárcenas \& Rosell 2007; Ribotta et al., 2004), and taro mucilage is an example of a hydrocolloid with emulsifying power (Nagata et al., 2015). Mucilage is a gummy substance found in vegetables and is usually present in tropical roots and tubers; it is particularly abundant in taro (Huang et al., 2010; Nagata et al., 2015).

The emulsifying property of the mucilage results mainly from its protein content, with the presence of weakly polar amino acids, in particular leucine, isoleucine and tryptophan, and the presence of lipids possibly providing the lipophilic fraction (Huang et al., 2010; Njintang et al., 2014). Galactose and arabinose are the main monosaccharides present in taro mucilage (Huang et al., 2010; Jiang \& Ramsden, 1999; Nguimbou et al., 2014), and these are capable of forming a complex called Arabinogalactan which, as a consequence of the high protein percentage, forms a proteoglycan called arabinogalactan (AGP) with emulsifying power (Jiang \& Ramsden, 1999).

The addition of emulsifiers contributes to increasing the dough volume, which positively affects the softness of the bread crumbs. In addition, the bread crumb characteristics, alveolar distribution and texture in the sensory analysis were considered better than those of the control bread (Gomes-Ruffi et al., 2012). Thus, in a general way, the distribution and shape of the bread alveoli are important to the sensory qualities of the product.

Good quality bread must have the proper porosity, i.e., oval, uniform cells with no holes. Changes in these parameters demonstrate formulation or process errors such as: excess improvers, improper mixing, very hard dough, poor moulding, excessive fermentation and inadequate heat distribution in the oven. In addition, a very closed and compact crumb structure makes the bread dark and dull, (Ferreira et al., 2001). In this case, baked and later frozen breads were softer than frozen breads. This characteristic is due to the fact that dough has large, uniform alveoli that are well distributed in the bread crumb, in addition to factors such as water mobility, storage temperature and formulation, which influence the structure of the bread crumb (Eckardt et al., 2013). It is believed that the use of freeze-dried taro mucilage in the bread mass results in a better distribution of the alveoli, which improves the dough texture and, consequently, market acceptance of the product.

Thus, the aim of this study was to present methods to verify if the alveoli are uniformly distributed in the bread crumbs containing freeze-dried taro mucilage; that is, the hypothesis that the alveoli present in the bread crumbs present a distribution with complete spatial randomness (CSR) will be tested. Several statistical methods have been proposed, including testing the CSR null hypothesis in point configurations, e.g., methods based on event counting by quadrant, distances between nearer neighbour events and descriptor functions as shown by (Cressie \& Wikle, 1993; Diggle, 2013). 
In the present work, the authors defended the use of methods to characterize the first-order and secondorder properties of point processes in space. The analysis of the first-order properties was carried out by using a kernel estimator of local intensity (Diggle, 2013). For the analysis of second-order properties, the descriptor F-, G-, and K-functions were used in conjunction with the Monte Carlo simulation (Diggle, 2013). These methods were expected to characterize whether the bread sockets for the freeze dried taro mucilage were distributed in the dough in a regular, random or agglomerated way. To date, the authors have found no studies with these characteristics in the literature.

\section{Materials and methods}

\subsection{Description of the experimental data or material or raw material}

French bread type buns weighing $50 \mathrm{~g}$ were prepared using the following formulation: $40 \mathrm{~g}$ of fresh biological yeast; $20 \mathrm{~g}$ of salt and $564 \mathrm{~g}$ of potable water at $10^{\circ} \mathrm{C}$ for $1 \mathrm{~kg}$ of wheat flour classified according to farinography

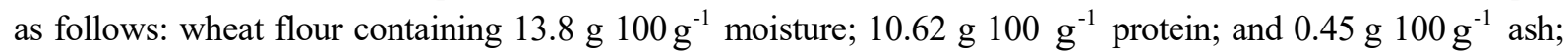

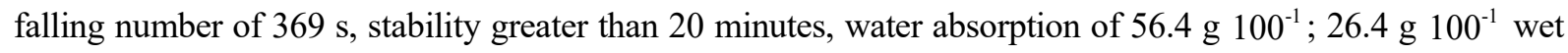

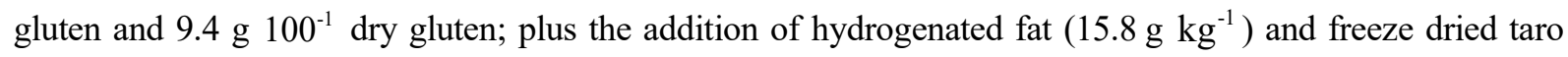
mucilage ( $\left.7.3 \mathrm{~g} \mathrm{~kg}^{-1}\right)$ following the recommendation of (Nagata et al., 2015).

The Taro (colocasia esculenta) mucilage was extracted according to recommendations made by

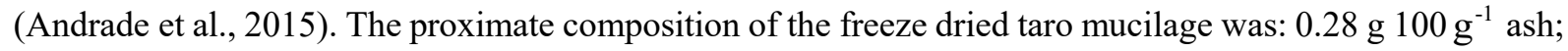

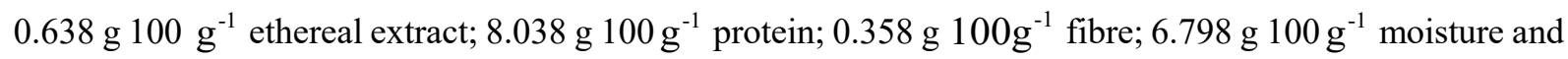

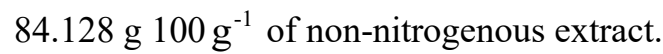

Three samples of French bread buns (S1-S3) produced in the Food Department of the Federal University of Lavras, Brazil were statistically analysed. For each bread sample, a cross sectional cut was made for the production of 3 slices. The middle slice was scanned using an HP deskjet 3040 with a 200 dpi colour scanner. The images obtained were treated by the ImageJ software using the following macro: enhance contrast $0.4 \%$, smooth, adjust colour threshold set in black and white. The samples were then analysed using Image-Pro Plus 4.5 image software, Media Cybernetics, Inc., USA. These images were obtained in pixels, to be transformed into $\left(\mathrm{cm}^{2}\right)$, and the conversion was done using a rectangular image of $8 \mathrm{~cm}^{2}$ that had 53735 pixels.

The following alveolar parameters were determined: mean number of alveoli, alveolar area $\left(\mathrm{cm}^{2}\right)$, mean diameter of the alveoli $(\mathrm{mm})$ and mass area $\left(\mathrm{cm}^{2}\right)$. For the application of point process methods, each alveolus of the bread was treated as a point defined by its coordinates. Thus a map was obtained in a flat region, with the location of all the alveoli present in the slice of bread.

The statistical analyses were carried out in the R environment (R Core Team, 2016) using the spatstat package (Baddeley \& Turner, 2005).

\subsection{Kernel Estimator}

Let $\left(x_{1}, x_{2}, \ldots, x_{n}\right)$ be the localizations (coordinates) of $n$ alveoli in a slice of bread, considered flat, with area $|A|$. According to Diggle (2013), the estimator of the local intensity of alveolus $\lambda(\boldsymbol{x})$ is given by Equation 1 .

$$
\widehat{\lambda_{\tau}}(\mathrm{x})=\sum_{\mathrm{i}=1}^{\mathrm{n}} \frac{1}{\tau^{2}} \mathrm{k}\left(\frac{\left(\mathrm{x}-\mathrm{x}_{\mathrm{i}}\right)}{\tau}\right)
$$

where $\tau>0$ is the parameter that determines the bandwidth (smoothing amount) and $k($.$) is a bivariate$ probability density function known as the kernel, which is symmetric in relation to the origin. A quartic 
function can be used as an alternative to $k($.$) , and in this case the intensity estimator \hat{\lambda}(\boldsymbol{x})$ can be expressed as.

$$
\widehat{\lambda}_{\tau}(\boldsymbol{x})=\sum_{i=1}^{n} \frac{3}{\pi \tau^{2}}\left(1-\frac{h_{i}^{2}}{\tau^{2}}\right)^{2}
$$

where $h_{i}$ is the distance between the point and the location of the observed alveolus (Equation 2).

\subsection{K Function}

The K function was proposed by Ripley (1977) as a tool to evaluate the second-order properties of a point process. The theoretical $\mathrm{K}$ function of a stationary point process is defined by $K(t)=\lambda^{-1} E$ (number of new events within a distance $\mathrm{t}$ from an arbitrary event). According to the CSR hypothesis, the function $\mathrm{K}$ is given by $K(t)=\pi t^{2}$. An estimator for $K(t)$ proposed by (Ripley, 1977) that corrects edge effects is given by

$$
\hat{K}(t)=\frac{|A|}{n^{2}} \sum_{i=1}^{n} \sum_{j=1}^{n} \frac{I_{t}\left(u_{i j}\right)}{w_{i j}}
$$

In Equation 3, $u_{i j}$ is the distance between the alveoli $\mathrm{i}$ and $\mathrm{j}(i \neq j), I_{t}\left(u_{i j}\right)$ is an indicator function that assumes the value 1 when $u_{i j}$ is less than the distance $t, \mathrm{n}$ is the number of alveoli in the bread slice (Area $|A|$ ), and $w_{i j}$ is a weighting factor that represents the ratio of the circumference of the circle around the alveolus $i$, passing through the alveolus $j$, which is found inside the area of the bread slice.

One way to analyse the estimates of the $K$ function of an observed point congruence is to use an auxiliary function $L$ as proposed by Besag (1977), which linearizes the $K$-function, stabilizes the variance and, consequently, facilitates its graphic interpretation. One of the estimators of the $L$ function is given by: $\hat{L}(t)=\sqrt{\hat{K}(t) / \pi}$.

\subsection{The $F$ and $G$ Functions}

The function F was proposed by Ripley (1977) and is based on the distance $\mathrm{x}$, that is, the distance between an arbitrary point (not the location of an alveolus) and the nearest alveolus. The function $\mathrm{F}$ is denoted by the distribution function $F(x)=P\{$ (the distance from an arbitrary point to the nearest event) $\}$. Under the CSR null hypothesis, the theoretical $\mathrm{F}$ function is given by:

$F(x)=1-\exp \left(-\lambda \pi x^{2}\right), \quad x>0$

The simplest estimator of the $\mathrm{F}$ function with corrected edge effect is given by equation: $\hat{F}(x)=\frac{\sum_{i=1}^{n} I_{x}\left(x_{i}, r_{i}\right)}{\sum_{i=1}^{n} I_{x}\left(r_{i}\right)}, \quad x>0$

where $m$ is the number of alveoli in the bread slice, $x_{i}$ denotes the distances of the $\mathrm{i}^{\text {th }}$ arbitrary point (between $n$ available points) to the nearest alveolus, between the $n$ alveoli observed, $I_{x}\left(r_{i}\right)$ is an indicator function that assumes a value of 1 when $x_{i} \leq x, r_{i}$ is the distance from each alveolus to the point nearest to 
the edge of $|A|$ and $I_{x}\left(x_{i}, r_{i}\right)$ is an indicator function that assumes the value 1 when $x_{i} \leq x$ and $r_{i} \geq x$. To choose the arbitrary $m$ points, one can use a regular grid $k \times k$, where $k \cong \sqrt{n}$.

The function $\mathrm{G}$ is based on the distance $y$, that is, the distance between the two nearest alveoli. It is given by the xpression $\mathrm{G}(\mathrm{y})=\mathrm{P}$ \{distance from an arbitrary event to another nearest event, at most $\mathrm{y}$ \}. The theoretical $\mathrm{G}$ function using the CSR null hypothesis and the corrected edge estimator of G(y) are given by equations analogous to Equation 4 and Equation 5, respectively, by substituting distance $x$ by distance $y$.

\subsection{Formal method for testing the hypothesis of Complete Spatial Randomness}

An approach based on Monte Carlo simulations to test the CSR null hypothesis was proposed by Diggle (2013). This approach compares the observed distribution function and the expected distribution function according to the CSR hypothesis. For the F function, the test statistic is given by:

$$
F I_{i}=\int_{0}^{x_{0}}\left\{\hat{F}_{i}(x)-\left[1-\exp \left(-\lambda \pi x^{2}\right)\right]\right\}^{2} d x ; \quad i=2, \ldots, s .
$$

The FI statistic has no known sample distribution, and thus this distribution can be obtained by Monte Carlo simulation. Let $\hat{F}_{1}(x)$ be the function $\mathrm{F}$ of a punctual observed configuration with $n$ events, as defined in Equation 6 and $\hat{F}_{2}(x), \ldots, \hat{F}_{s}(x)$ the $\mathrm{F}$ functions calculated from the $s$ Monte Carlo simulations according to the CSR hypothesis, each one with $n$ events.

The statistics of $F I_{i}$ are calculated for the configuration observed and simulated. The value of $F I_{i}$ is compared with the values $\widehat{F I}_{2}(x), \ldots, \widehat{F I}_{s}(x)$ obtained from the simulated configurations. If $F I_{1}$ is between the highest values of $\widehat{F I}_{2}(x), \ldots, \widehat{F I}_{s}(x)$, then it appears that the configuration is not according to the CSR. If one assumes that $F_{1}=F_{(j)}$ for some $j \in\{1, \ldots s\}$, one must reject the CSR hypothesis if the $P_{\text {value }}=((s+1-j) / 2) \leq \alpha$.

This procedure can be carried out anomalously for functions $\mathrm{K}$ and $\mathrm{G}$.

\subsection{Graphical method for testing the hypothesis of complete spatial randomness}

The formal test presented above does not indicate the direction (regularity or grouping alveoli) of the rejection of the null hypothesis. The graphical method, presented below, fills this gap.

Let $\hat{F}_{1}(x)$ be a function $\mathrm{F}$ of a pattern of observed points with $n$ events. By simulation, $s-1$ sets of $n$ events are generated, assuming CSR. For these $s-1$ simulated data sets, the upper and lower simulation envelopes, respectively, are calculated as: $U(x)=\max \hat{F}_{i}(x), \quad i=2, \ldots, s$ e $L(x)=\min \hat{F}_{i}(x), \quad i=2, \ldots, s$.

A graph is constructed of $\hat{F}_{1}(x), U(x), L(x)$ (ordinates) against the distances $x$. If the curve represented by $\hat{F}_{1}(x)$ lies inside the simulated envelopes, the CSR hypothesis is not rejected. If $\hat{F}_{1}(x)$ falls below the smallest simulation envelope for any distance, there are indications that the alveoli present a distribution that is typical of a pattern that exhibits clusters. Otherwise, if $\hat{F}_{1}(x)$ lies above the simulation envelope at the top, for any distance, there is evidence that the alveoli exhibit a regular pattern. 
It is possible to construct the simulation envelopes for the functions $\mathrm{G}$ and $\mathrm{K}$ in a manner analogous to that used for the function F; however, the interpretations that detect regularity and grouping are carried out in a way that is the inverse of function $\mathrm{F}$.

\section{Results and discussion}

The first requirement in any data analysis is to observe the data that are to be analysed. The visualization of the spatial pattern means mapping the alveoli in the bread slice, and the plotting of the location of each alveolus as a point map is a natural tool for visualizing the spatial distribution. This map provides an idea of the alveolar distribution and may show some obvious pattern of alveolar distribution in the samples. The point maps of the samples (S1, S2, S3) are shown in Figure 1.
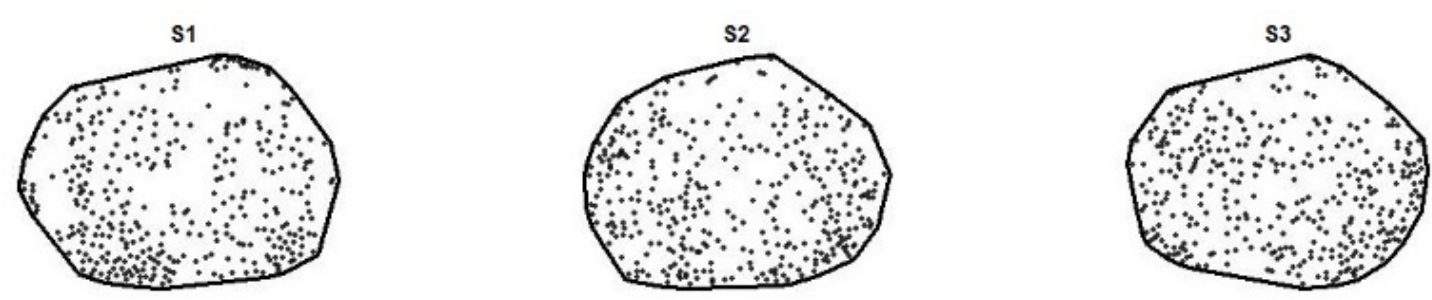

Figure 1. Localization map of the alveoli in the French bread bun slices of the samples (S1, S2, S3).

A visual inspection of Figure 1 shows that it is very difficult to assess the nature of the pattern of the points based on this information, in other words, whether there is a tendency for clustering or regularity of the alveoli in the bun slices.

Table 1 shows the overall intensity $\lambda$ for the three samples, indicating the presence of approximately 16 alveoli on average per $\mathrm{cm}^{2}$ of bread. However, Figure 1 seems to show that by using only the global mean to characterize the distribution of the alveoli in bread leads to an inaccurate interpretation. A more advanced statistical tool for analysing the expected number of alveoli per unit area is the use of an estimate of the local alveoli intensity using, for example, the kernel intensity estimator (section 2.2).

Table 1. Summarized sample data.

\begin{tabular}{cccc}
\hline Sample & Number of alveoli & Area $\left(\mathbf{c m}^{2}\right)$ & Intensity $(\boldsymbol{\lambda})$ \\
\hline S1 & 339 & 21.04 & 16.111 \\
S2 & 348 & 21.17 & 16.435 \\
S3 & 346 & 21.24 & 16.286 \\
\hline
\end{tabular}

To estimate the local intensity, the most important factor is to choose the appropriate bandwidth $(\tau)$. If the bandwidth tends to zero, the intensity is estimated as a series of peaks in individual observations, whereas if the bandwidth becomes large, all details will be obfuscated. Diggle (2013) suggested adopting $\tau=0.68 n^{-0.2}$ for unitary areas. Since the bun slice areas did not have unit areas, a value that minimized the likelihood function of the point process obtained by cross-validation was adopted, as suggested by Loader (2006). Diggle (2013) stated that the choice of kernel function was of secondary importance since any kernel function (e.g., Gaussian, quartic) leads to the same results. In the present work, the quartic kernel was used (Equation 2). Figure 2 shows the maps smoothed by the kernel intensity estimator $\hat{\lambda}_{\tau}$. 
s1

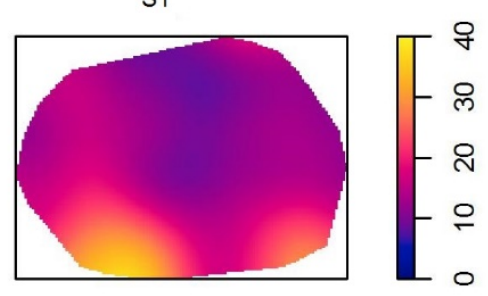

S2

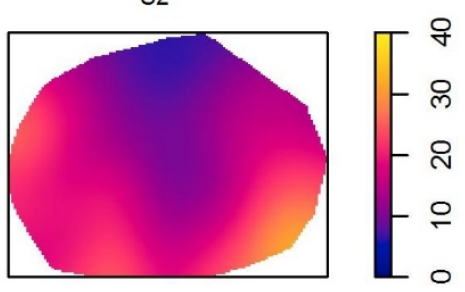

\$3

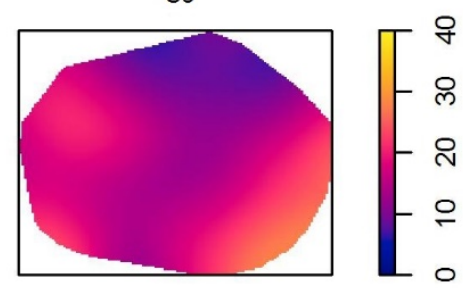

Figure 2. Estimates of local intensity using the quartic kernel estimator.

The analysis of the local intensity is important since the alveolar distribution in the bread crumbs tells us a lot about the action of the emulsifiers. For example, studies by Scheuer et al. (2014) and Polaki et al. (2010) showed that when the fat was replaced by an emulsifying agent, in this case enzymatically modified corn starch and polydextrose, respectively, the alveolar intensity was larger and more homogeneous, in addition to leading to smaller alveolar sizes.

The samples present in Figure 2 show both areas where the local alveolar intensity is much larger than the global intensity, and also areas where the local intensity is much lower than the overall mean. The upper parts of the bun slices appear to have a tendency for lower alveolar intensities, so there is evidence that the alveolar distribution throughout the bun slice may not be random.

However, one should not draw conclusions on the alveolar distribution in bread by analysing only the intensities (first-order properties), but should also analyse possible interactions between alveoli (second-order properties). For this, formal tests were carried out against the hypothesis of complete spatial randomness using the functions F, G and $\mathrm{K}(\mathrm{s}=100)$ and the results are presented in Table 2.

Table 2. P-values of the tests against the hypothesis of complete spatial randomness based on the integral of the quadratic difference of the functions $F, G$ and $K$.

\begin{tabular}{cccc}
\hline \multirow{2}{*}{ Test } & \multicolumn{3}{c}{ Sample } \\
\cline { 2 - 4 } & S1 & S2 & S3 \\
\hline F-function & 0.35 & 0.48 & 0.25 \\
G-function & 0.01 & 0.01 & 0.01 \\
K-function & 0.01 & 0.01 & 0.01 \\
\hline
\end{tabular}

The p-values were attached based on 99 Monte Carlo simulations $(s=100)$ of a homogeneous Poisson process.

The results presented in Table 2 show that the tests based on the $\mathrm{G}$ and $\mathrm{K}$ functions lead to an emphatic rejection of the CSR hypothesis for all the samples $(p<0.05)$, while the F-function suggests the acceptance of CSR for all the samples. The G-function is able to detect regularity more powerfully, while the F-function is able to detect event clusters more powerfully (Diggle, 2013). Thus, it is probable that the distribution of the alveoli in the bread dough may be regular. In order to be sure of the nature of the alveolar distribution, simulation envelopes (section 2.2) must be adopted for the F, G and K functions. The envelopes are shown in Figures 3, 4 and 5. 
s1

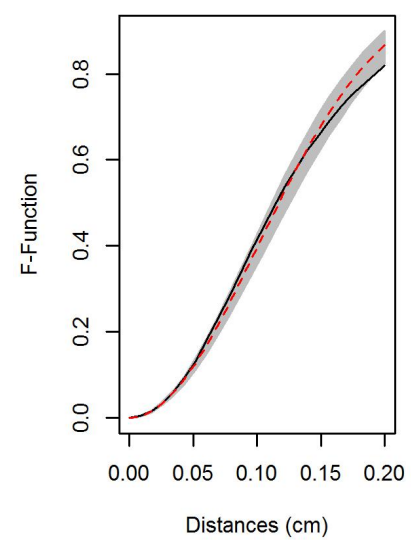

S2

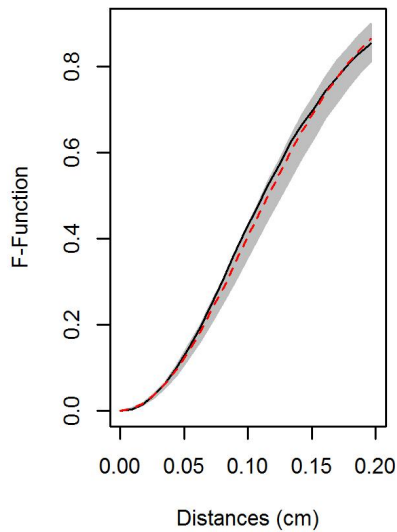

s3

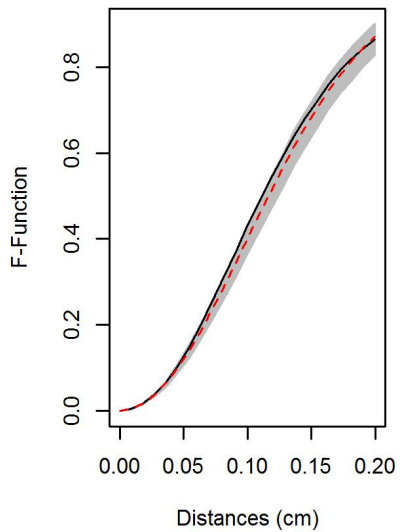

Figure 3. Envelopes with 99 simulations (grey colour) against the CSR hypothesis of a Poisson process (red dotted lines) for the empirical F (solid line) functions in samples S1, S2, and S3.

s1

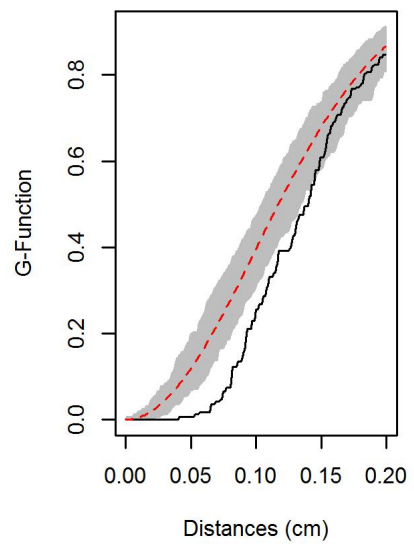

S2

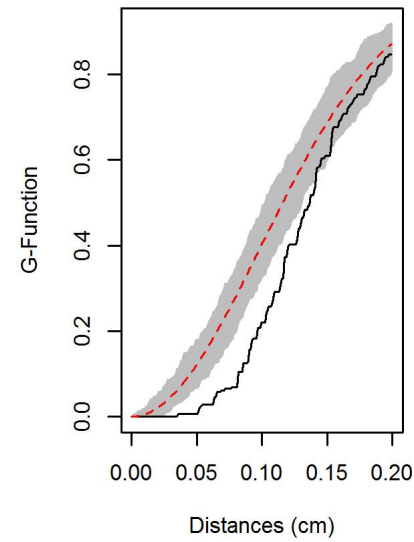

S3

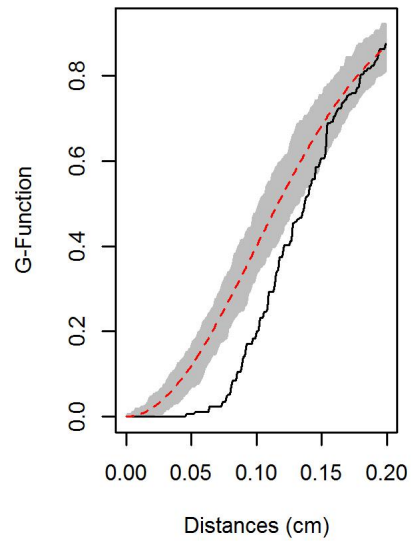

Figure 4. Envelopes with 99 simulations (grey colour) against the CSR hypothesis of a Poisson process (red dotted lines) for the empirical G functions (solid line) in samples S1, S2, and S3.

s1

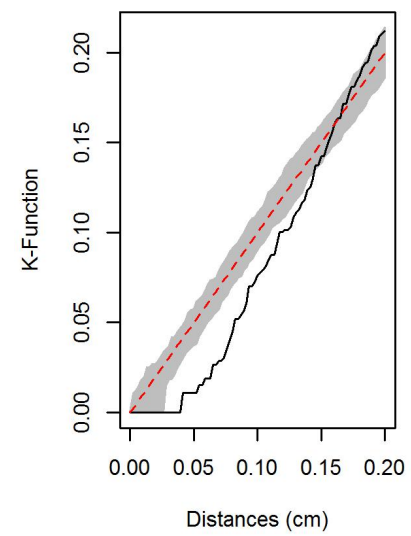

S2

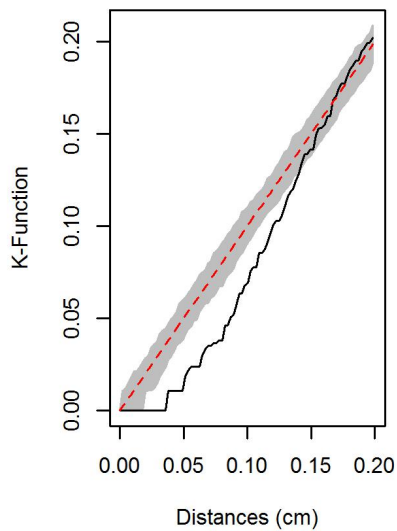

s3

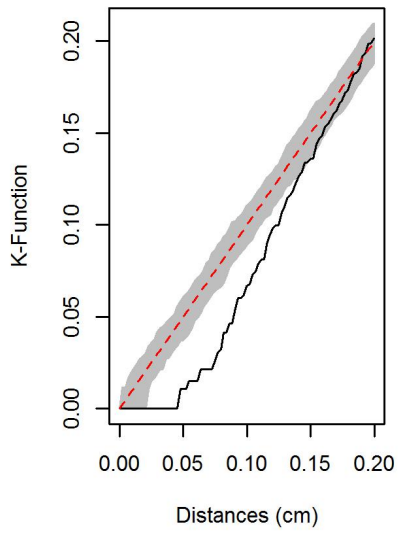

Figure 5. Envelopes with 99 simulations (grey colour) against the CSR hypothesis of a Poisson process (red dotted lines) for the empirical L functions (solid line) in samples S1, S2, and S3. 
It can be seen that the empirical $\mathrm{F}$ function represents practically all of the simulation envelopes, while the empirical functions $\mathrm{G}$ and $\mathrm{K}$ are below the simulation envelopes, indicating a rejection of the hypothesis of complete spatial randomness in the direction of regularity.

An interesting feature observed in the envelopes of the $G$ function is the absence of neighbouring alveoli for small distances of up to $0.05 \mathrm{~cm}$. This inhibitory mechanism can be explained by the fact that, in the analysis, only the positions (centres) of the alveoli were considered, the areas of the alveoli being ignored. Thus, there will always be a minimum distance corresponding to the sizes of the alveolar ray that were not considered in the analyses. The same explanation can be given for the $\mathrm{L}$ function.

The results above show the importance of using the three functions for the analysis of the interaction between the alveoli, since each of these functions has greater power in the detection of certain characteristics of the standard, and therefore the use of all functions leads to a more sensitive analysis than when used alone. For example, the analysis based on the $\mathrm{G}$ function is more sensitive for regularity, unlike the analysis with the CSR $\mathrm{F}$ function, which is more sensitive for the detection of clustering. This behaviour explains the differences observed between the results provided by the $\mathrm{F}$ and $\mathrm{G}$ functions. The $\mathrm{K}$ function is considered equally powerful in terms of the ability to detect configurations with both clusters and regularity (Diggle, 2013).

The analysis presented here is valuable in suggesting the spatial structure that may be present in the data, since the use of emulsifiers in baking products contributes to the improvement of the kernel structure with smaller and closer alveoli, brighter kernels and greater uniformity in the f cell size (Stampfli \& Nersten, 1995); adding fat to the formulation of the buns has the function of retaining the air in the mass during mixing and baking. The fat crystals absorbed by the air-water interface melt and allow the water-fat interface to expand into a bubble. The size of these air bubbles is related to the different amounts of air incorporated in the mass. The presence of a large number of adsorbed crystals allows the bubbles to expand without rupture, and this allows the formation of a kernel with different textures (Polaki et al., 2010).

In fact, the previous analysis indicated wide regularity on a small scale. Thus, it is believed that the use of taro mucilage provides a mass with regularly distributed alveoli, since the complexes formed between the carbohydrates and proteins present in the mucilage act as tensoactive compounds in the aqueous phase that permeates the alveolar wall, allowing the formation of an interface between the phases and producing a larger number of small alveoli. According to (Polaki et al., 2010), the pore distribution reveals important information about the bread structure. In their research, they classified the pores into small (area $<4 \mathrm{~mm}^{2}$ ), medium $\left(\right.$ area $<4-8 \mathrm{~mm}^{2}$ ) and large $\left(\right.$ area $>8 \mathrm{~mm}^{2}$ ) and associated them with the sensory characteristics; in other words, the size of the alveoli is directly connected to the quality of the mass and thus the taste of the bread. In this study, the size of the alveoli was not used in the analysis (the marked dot pattern), which may lead to a comprehensive conclusion regarding the data.

\section{Conclusion}

This paper puts forward a comprehensive analysis of the spatial distribution of the breadcrumb alveoli obtained from dough with taro mucilage as the emulsifier. The analysis clearly showed that the functional pattern of the descriptors described different properties of spatial point patterns. The $\mathrm{F}, \mathrm{G}$, and $\mathrm{K}$ functions are powerful tools for summarizing essential pattern properties and therefore ideal for testing the CRS. The results based on the images of three bun slices showed a deviation that was statistically significant towards regularity in the CRS. Thus, it is believed that the use of the taro mucilage provides a dough with regularly distributed alveoli indicating an emulsifying effect that will be beneficial to the texture and consequently to the quality of the bread.

\section{Acknowledgements}

This work was carried out during a scholarship supported by the International Cooperation Program CAPES at the Federal University of Lavras, financed by CAPES - Brazilian Federal Agency for the Support and Evaluation of Graduate Education within the Ministry of Education of Brazil. 


\section{References}

Andrade, L. A., Nunes, C. A., \& Pereira, J. (2015). Relationship between the chemical components of taro rhizome mucilage and its emulsifying property. Food Chemistry, 178, 331-338. PMid:25704720. http://dx.doi.org/10.1016/j.foodchem.2015.01.094 Baddeley, A., \& Turner, R. (2005). Spatstat: an R package for analyzing spatial point patterns. Journal of Statistical Software, 12(6), 1-42. http://dx.doi.org/10.18637/jss.v012.i06

Bárcenas, M. E., \& Rosell, C. M. (2007). Different approaches for increasing the shelf life of partially baked bread: Low temperatures and hydrocolloid addition. Food Chemistry, 100(4), 1594-1601. http://dx.doi.org/10.1016/j.foodchem.2005.12.043

Besag, J. E. (1977). Comments on Ripley's paper. Royal Statistical Society Journal, 39(1), 193-195.

Cressie, N., Wikle, C. K. (1993). Statistics for spatio-temporal data. John Wiley \& Sons.

Diggle, P. J. (2013). Statistical analysis of spatial and spatio-temporal point patterns. CRC Press.

Eckardt, J., Öhgren, C., Alp, A., Ekman, S., Åström, A., Chen, G., Swenson, J., Johansson, D., \& Langton, M. (2013). Long-term frozen storage of wheat bread and dough-Effect of time, temperature and fibre on sensory quality, microstructure and state of water. Journal of Cereal Science, 57(1), 125-133. http://dx.doi.org/10.1016/j.jcs.2012.10.007

Ferreira, S. M. R., Oliveira, P. V., \& Pretto, D. (2001). Parâmetros de qualidade do pão francês. Boletim do Centro de Pesquisa e Processamento de Alimentos, 19(2), 1-11. http://dx.doi.org/10.5380/cep.v19i2.1240

Goesaert, H., Brijs, K., Veraverbeke, W. S., Courtin, C. M., Gebruers, K., \& Delcour, J. A. (2005). Wheat flour constituents: how they impact bread quality, and how to impact their functionality. Trends in Food Science \& Technology, 16(1), 12-30. http://dx.doi.org/10.1016/j.tifs.2004.02.011

Gomes-Ruffi, C. R., Cunha, R. H., Almeida, E. L., Chang, Y. K., \& Steel, C. J. (2012). Effect of the emulsifier sodium stearoyl lactylate and of the enzyme maltogenic amylase on the quality of pan bread during storage. Lebensmittel-Wissenschaft + Technologie, 49(1), 96-101. http://dx.doi.org/10.1016/j.Iwt.2012.04.014

Huang, C. C., Lai, P., Chen, I. H., Liu, Y. F., \& Wang, C. C. (2010). Effects of mucilage on the thermal and pasting properties of yam, taro, and sweet potato starches. Food Science and Technology (Campinas), 43(6), 849-855.

Jiang, G., \& Ramsden, L. (1999). Characterisation and yield of the arabinogalactan-protein mucilage of taro corms. Journal of the Science of Food and Agriculture, 79(5), 671-674. http://dx.doi.org/10.1002/(SICl)1097-0010(199904)79:5<671::AIDJSFA233>3.0.CO;2-H

Krog, N. (1981). Theoretical aspects of surfactants in relation to their use in breadmaking. Cereal Chemistry, 1(1), 1-11. Loader, C. (2006). Local regression and likelihood. Springer Science \& Business Media.

Nagata, C. L., Andrade, L. A., \& Pereira, J., (2015). Optimization of taro mucilage and fat levels in sliced breads. Journal of Food Science and Technology, 52(9), 5890-5897. PMid:26345005. http://dx.doi.org/10.1007/s13197-014-1655-5

Nguimbou, R. M., Boudjeko, T., Njintang, N. Y., Himeda, M., Scher, J., \& Mbofung, C. M. (2014). Mucilage chemical profile and antioxidant properties of giant swamp taro tubers. Journal of Food Science and Technology, 51(12), 3559-3567. PMid:25477624. http://dx.doi.org/10.1007/s13197-012-0906-6

Njintang, N. Y., Boudjeko, T., Tatsadjieu, L. N., Nguema-Ona, E., Scher, J., \& Mbofung, C. M. (2014). Compositional, spectroscopic and rheological analyses of mucilage isolated from taro (Colocasia esculenta L. Schott) corms. Journal of Food Science and Technology, 51(5), 900-907. PMid:24803696. http://dx.doi.org/10.1007/s13197-011-0580-0

Polaki, A., Xasapis, P., Fasseas, C., Yanniotis, S., \& Mandala, I. (2010). Fiber and hydrocolloid content affect the microstructural and sensory characteristics of fresh and frozen stored bread. Journal of Food Engineering, 97(1), 1-7. http://dx.doi.org/10.1016/j.jfoodeng.2009.04.031

R Core Team. (2016). A language and environment for statistical computing. Vienna: The R Foundation. Retrieved in 2018, January 19, from https://www.R-project.org/

Ribotta, P. D., Pérez, G. T., León, A. E., \& Añón, M. C. (2004). Effect of emulsifier and guar gum on micro structural, rheological and baking performance of frozen bread dough. Food Hydrocolloids, 18(2), 305-313. http://dx.doi.org/10.1016/S0268005X(03)00086-9

Ripley, B. D. (1977). Modelling spatial patterns. Journal of the Royal Statistical Society. Series A (General), 1(11), $172-212$.

Scheuer, P. M., Mattioni, B., Barreto, P. L. M., Montenegro, F. M., Gomes-Ruffi, C. R., Biondi, S., Kilpp, M., \& Francisco, A. (2014). Effects of fat replacement on properties of whole wheat bread. Brazilian Journal of Pharmaceutical Sciences, 50(4), 703-712. http://dx.doi.org/10.1590/S1984-82502014000400005

Stampfli, L., \& Nersten, B. (1995). Emulsifiers in bread making. Food Chemistry, 52(4), 353-360. http://dx.doi.org/10.1016/03088146(95)93281-U 